\title{
Protective effect of glycyrrhizin on myocardial ischemia/reperfusion injury-induced oxidative stress, inducible nitric oxide synthase and inflammatory reactions through high-mobility group box 1 and mitogen-activated protein kinase expression
}

\author{
XIANGNA CAI ${ }^{1}, \mathrm{XIN}_{\mathrm{WANG}}{ }^{2}, \mathrm{JILIN} \mathrm{LI}^{2}$ and SHUYING CHEN ${ }^{2}$ \\ Departments of ${ }^{1}$ Plastic Surgery and ${ }^{2}$ Cardiology, \\ First Affiliated Hospital of Shantou University Medical College, Shantou, Guangdong 515041, P.R. China
}

Received November 10, 2015; Accepted December 9, 2016

DOI: $10.3892 /$ etm.2017.4617

\begin{abstract}
Glycyrrhizin, which is a type of perennial leguminous caudex, has been used in various Asian countries, including P.R. China, India and Japan, for thousands of years. The present study was designed to investigate the protective effect of glycyrrhizin on myocardial ischemia/reperfusion (I/R) injury through oxidative stress, inducible nitric oxide synthase (iNOS), and inflammatory reactions via high-mobility group box 1 (HMGB1) and mitogen-activated protein kinase (MAPK) expression. Sprague-Dawley rats were divided into five groups: Sham; myocardial I/R injury + non-treated; myocardial I/R injury $+2 \mathrm{mg} / \mathrm{kg}$ glycyrrhizin; myocardial I/R injury $+4 \mathrm{mg} / \mathrm{kg}$ glycyrrhizin; and myocardial I/R injury $+10 \mathrm{mg} / \mathrm{kg}$ glycyrrhizin. Pre-treatment with glycyrrhizin significantly reduced infarct size and inhibited creatine kinase, creatine kinase-MB, lactate dehydrogenase and cardiac troponin $\mathrm{T}$ activities in rats with myocardial I/R injury. Furthermore, glycyrrhizin treatment significantly suppressed oxidative stress, iNOS protein expression and inflammatory reactions in rats with myocardial I/R injury. Additionally, treatment with glycyrrhizin significantly decreased the release of HMGB1 from the cerebral cortex into the serum in rats with myocardial I/R injury. Notably, glycyrrhizin significantly suppressed p-ERK, p-p38 MAPK and p-c-Jun N-terminal kinase protein expressions, and promoted extracellular signal-regulated kinase protein expression in rats with myocardial I/R injury. Collectively, the present study
\end{abstract}

Correspondence to: Ms. Shuying Chen, Department of Cardiology, First Affiliated Hospital of Shantou University Medical College, 57 Changping Road, Shantou, Guangdong 515041, P.R. China E-mail: caixnxnst@163.com

Key words: glycyrrhizin, myocardial ischemia/reperfusion injury, oxidative stress, inducible nitric oxide synthase, inflammatory, high-mobility group box 1 , mitogen-activated protein kinase indicates that the protective effect of glycyrrhizin may reduce myocardial I/R injury through oxidative stress, iNOS and inflammatory reactions, via HMGB1 and MAPK expression.

\section{Introduction}

Acute myocardial infarction leads to ischemic necrosis of the myocardium, which is greatly detrimental to the health of the population (1). Each year, 800,000 individuals in America are diagnosed with myocardial infarction (2). Morbidity from myocardial infarction in China is increasing year by year (3). Timely opening of the coronary arteries in patients with myocardial infarction reduces the area of myocardial infarction and significantly decreases mortality rates (4). A clinically relevant phenomenon that occurs is myocardial ischemia/reperfusion (I/R) injury, which refers to damage to the myocardial structure after regaining blood perfusion to the ischemic myocardium (5). Cardiac muscle cells may also die and the area of myocardial necrosis may extend, which seriously affects the prognosis of patients with myocardial infarction (6). In clinical practice, myocardial I/R injury may result in the disorder of electrical activities in the myocardium, arrhythmia and cardiac insufficiency (7). Pathologically, obvious bleeding and infiltration of inflammatory cells in necrotic tissues after reperfusion may appear (8). Furthermore, microvascular endothelial cells are impaired and blood vessels are blocked, thus, effective reperfusion cannot be implemented (2).

An important ingredient of root extraction from liquorice is the water soluble acid, glycyrrhizin (Fig. 1), which consists of glucuronic acid and glycyrrhetinic acid (9). A prior study has indicated that glycyrrhizin is one of the most effective ingredients of liquorice, which has anti-ulcer, anti-allergic, anti-oxidant, immunomodulatory, anti-viral and anti-cancer effects (10). Furthermore, it has the functions of liver protection and membrane stabilization. Glycyrrhizin has been widely used in Europe and the Middle East (11).

The aim of the present study was to investigate the protective effect of glycyrrhizin, as well as the related mechanisms, against myocardial I/R injury in model rats. 


\section{Materials and methods}

Animals, groups and experimental design. A total of 48 male Sprague-Dawley rats, weighing 280-320 g, were obtained from the Experimental Animal Centre of the Sichuan Neurosurgical Institute (Sichuan, China) and were maintained in standard conditions: $25^{\circ} \mathrm{C} ; 50 \%$ humidity; a 12 -h light cycle (8:00-20:00); and free access to laboratory chow and water. Rats were divided into five groups: Sham group (Sham; $\mathrm{n}=8$ ); myocardial I/R injury + non-treated group (NS; $\mathrm{n}=10)$; myocardial I/R injury $+2 \mathrm{mg} / \mathrm{kg}$ glycyrrhizin $(\mathrm{n}=10)$; myocardial I/R injury $+4 \mathrm{mg} / \mathrm{kg}$ glycyrrhizin $(\mathrm{n}=10)$; and myocardial I/R injury $+10 \mathrm{mg} / \mathrm{kg}$ glycyrrhizin $(\mathrm{n}=10)$. In the myocardial I/R injury $+2,4$ or $10 \mathrm{mg} / \mathrm{kg}$ glycyrrhizin groups, myocardial I/R injury rats were administered glycyrrhizin at $0,2,4$ or $10 \mathrm{mg} / \mathrm{kg}$ by intraperitoneal injection at $30 \mathrm{~min}$ prior to ischemia. The sham and NS groups were treated with an equal volume of normal saline.

In vivo myocardial I/R injury model. Sprague-Dawley rats were anesthetized with $40 \mathrm{mg} / \mathrm{kg}$ of sodium pentobarbital (intraperitoneally, Sinopharm Chemical Reagent Co., Ltd., Shanghai, China). Myocardial I/R injury was induced by left thoracic incision to expose the heart and a $6 / 0$ silk suture was sewn around the left anterior descending coronary. The slipknot was released for reperfusion for $24 \mathrm{~h}$, following ischemia for $30 \mathrm{~min}$.

Determination of myocardial infarct size. Sprague-Dawley rats were sacrificed using the beheaded method and the hearts were subsequently harvested. Hearts were stained with $1.5 \%$ Evans blue (Sigma-Aldrich; Merck Millipore, Darmstadt, Germany), washed with saline and stored at $-80^{\circ} \mathrm{C}$. Subsequently, the frozen hearts were cut into 5-7 $\mathrm{mm}$ slices and incubated with $1.2 \%$ triphenyltetrazolium chloride (TTC) (Ameresco, Inc., Framingham, MA, USA) for $15 \mathrm{~min}$ at $37^{\circ} \mathrm{C}$. Viable non-ischemic myocardium presented as blue (stained with Evans blue) and ischemic, viable myocardium was red (stained with TTC). The ratio of infarct size was calculated as red area /total area of heart, and expressed as a percentage.

Measurement of aspartate aminotransferase (AST), lactate dehydrogenase $(L D H)$ alanine aminotransferase $(A L T)$ and creatine kinase $(C K)$. Blood samples were obtained from the right carotid artery and centrifuged at $1,000 \mathrm{xg}$ for $15 \mathrm{~min}$ at $4^{\circ} \mathrm{C}$. ELISA assay kits were used to determine serum AST (cat. no. C010-2), LDH (cat. no. A020-2), ALT (cat. no. C009-1) and CK (cat. no. H197) levels according to the manufacturer's instructions (all Nanjing Jianchen Bioengineering Institute, Nanjing, Jiangsu, China).

Measurement of glutathione (GSH) and glutathione peroxidase $(G S H-P X)$. Blood samples were obtained from the right carotid artery and centrifuged at $1,000 \mathrm{x}$ g for $15 \mathrm{~min}$ at $4^{\circ} \mathrm{C}$. Assay kits were used to determine serum GSH and GSH-PX levels (cat. nos. A006-2 and A005) according to the manufacturer's instructions (Nanjing Jianchen Bioengineering Institute).

Reverse transcription-quantitative polymerase chain reaction (RT- $q P C R)$. Total RNA was extracted from heart tissue samples using TRIzol reagent (Invitrogen; Thermo Fisher Scientific Inc., Waltham, MA, USA), and DNase I (Invitrogen; Thermo Fisher Scientific Inc.) was used to remove genomic DNA, and RNA samples $(1 \mu \mathrm{g})$ were used for cDNA synthesis using an RT-PCR kit (Roche Diagnostics GmbH, Mannheim, Germany). Total RNA (200 ng) was subjected to RT-qPCR using SYBR Green Premix (Takara Biotechnology Co., Ltd., Dalian, China) on an ABI 7500 Real-time PCR system (Thermo Fisher Scientific, Inc.). Primers used to amplify the fragment of HMGB1 and inducible nitric oxide synthase (iNOS) were designed as follows: HMGB1, forward 5'-CTGATGCAGCTTATACGAAG-3' and reverse 5'-TCA GGTAAGGAGCAGAACAT-3'; iNOS, forward 5'-GCATCC CAAGTACGAGTGGT-3' and reverse 5'-GAAGGCGTAGCT GAACAAGG-3'; and GAPDH, forward 5'-CCATCACTGCCA CTCAGAAGA-3' and reverse 5'-CATGAGGTCCACCACCCT GT-3'. The PCR consisted of an initial denaturation step at $94^{\circ} \mathrm{C}$ for $5 \mathrm{~min}$ followed by 40 cycles at $94^{\circ} \mathrm{C}$ for $30 \mathrm{sec}, 58^{\circ} \mathrm{C}$ for $30 \mathrm{sec}$ and $72^{\circ} \mathrm{C}$ for $45 \mathrm{sec}$, with a final extension at $72^{\circ} \mathrm{C}$ for $10 \mathrm{~min}$. The relative gene expression was calculated using the $2^{-\Delta \Delta C \mathrm{q}}$ method (12).

Measurement of nuclear factor kappa-light-chain-enhancer of activated B cells-p65 (NF- $\kappa B-p 65)$, tumor necrosis factor- $\alpha$ $(T N F-\alpha)$, interleukin-1 $\beta(I L-1 \beta)$ and IL-6. Blood samples were obtained from the right carotid artery and centrifuged at $1,000 \times g$ for $15 \mathrm{~min}$ at $4^{\circ} \mathrm{C}$. ELISA assay kits were used to detect serum NF- $\kappa \mathrm{B}-\mathrm{p} 65$ (cat. no. H202), TNF- $\alpha$ (cat. no. R019), IL-1 $\beta$ (cat. no. H002) and IL-6 (cat. no. R016) levels according to the manufacturer's instructions (Nanjing Jianchen Bioengineering Institute).

Western blot assays. Total protein was extracted from heart tissue samples and homogenized in $0.5 \mathrm{ml}$ of radio-immunoprecipitation assay buffer. The supernatant was collected for protein concentration, using the $\mathrm{BCA}$ protein assay reagent kit (Beijing Boaosen Biotechnology Co., Ltd., Beijing, China). Equal quantities of protein $(50 \mu \mathrm{g})$ samples were separated using 6-12\% SDS-PAGE and transferred onto polyvinylidene fluoride membrane (EMD Millipore, Billerica, MA, USA). Membranes were blocked with 5\% skimmed milk for $2 \mathrm{~h}$ and incubated with rabbit anti-phosphorylated (p)-p38 (1:4,000; cat. no. 4511), rabbit anti p-JNK (1:2,000; cat. no. 4668) and p-extracellular signal-regulated kinase (ERK; 1:3,000; 4376; all Cell Signaling Technology, Inc., Danvers, MA, USA), at $4^{\circ} \mathrm{C}$ overnight. Following washing with Tris-buffered saline solution with Tween-10, the membranes were incubated with a horseradish peroxidase-conjugated secondary antibody $(1: 2,000$; cat. no. bs-0295G; Beijing Boaosen Biotechnology Co., Ltd.) at $37^{\circ} \mathrm{C}$ for $1 \mathrm{~h}$. Blots were visualized with a Low Background Luminescence ECL Detection kit (Nanjing Jianchen Bioengineering Institute) and quantified using the Image J 3.0 system (National Institutes of Health, Bethesda, MD, USA).

Statistical analysis. Experimental data were expressed as mean \pm standard deviation. SPSS 17.0 (SPSS, Inc., Chicago, IL, USA) software was used for statistical analysis of data, with significant within-group and between-group differences analyzed by Dunnett's test. $\mathrm{P}<0.05$ was considered to indicate a statistically significant difference. 


\section{Results}

Protective effect of glycyrrhizin on infarct size in rats with myocardial I/R injury. Infarct size of rats was measured by Evans blue/TTC staining in each of the five groups (Fig. 2). Glycyrrhizin significantly inhibited infarct size in myocardial I/R injury rats, inhibition was demonstrated to correspond with the increasing concentrations of glycyrrhizin administered when compared with the NS group $(\mathrm{P}<0.01$; Fig. 2$)$.

Protective effect of glycyrrhizin on AST, LDH, ALT and CK in rats with myocardial I/R injury. Plasma AST, LDH, ALT and CK levels were measured, which are important indicators of the extent of myocardial injury (13). Compared with the sham group, plasma AST, LDH and ALT levels were significantly increased as a result of myocardial I/R injury in rats, as was also depicted in the NS group compared with the sham-operated group $(\mathrm{P}<0.01)$; although, no significant increase was observed for CK (Fig. 3A-D, respectively). Increased levels of the indicators for myocardial injury were significantly hindered by treatment with $2-10 \mathrm{mg} / \mathrm{kg}$ glycyrrhizin $(\mathrm{P}<0.01)$; however, decreased levels of $\mathrm{LDH}$ in the 4 and $10 \mathrm{mg} / \mathrm{kg}$ groups were not statistically significant (Fig. 3A-D).

Protective effect of glycyrrhizin on oxidative stress in rats with myocardial I/R injury. Plasma GSH and GSH-PX levels significantly decreased after myocardial I/R injury, compared with the sham-operated group ( $\mathrm{P}<0.01$; Fig. $4 \mathrm{~A}$ and $\mathrm{B}$, respectively). When rats were pre-treated with $2-10 \mathrm{mg} / \mathrm{kg}$ glycyrrhizin, plasma GSH and GSH-PX levels were significantly elevated when compared with the levels observed in the NS group in myocardial I/R injury rats ( $\mathrm{P}<0.01$; Fig. $4 \mathrm{~A}$ and $\mathrm{B}$, respectively).

Protective effect of glycyrrhizin on iNOS in rats with myocardial I/R injury. To demonstrate that the protective effect of glycyrrhizin on myocardial I/R injury is associated with iNOS production, iNOS miRNA expression levels of myocardial I/R injury rats were determined. In the sham group, iNOS miRNA expression levels were significantly decreased when compared with the expression exhibited in myocardial I/R injury rats $(\mathrm{P}<0.01$; Fig. 5). Pre-treatment with glycyrrhizin resulted in a significant decrease in the iNOS miRNA expression of myocardial I/R injury groups when compared with the NS group $(\mathrm{P}<0.01$; Fig. 5$)$.

Protective effect of glycyrrhizin on inflammatory reactions in rats with myocardial I/R injury. The protective effect of glycyrrhizin on inflammatory reactions in myocardial I/R injury rats was investigated. Compared with the sham-operated group, NF- $\kappa$ B-p65TNF- $\alpha$, IL-1 $\beta$ and IL-6 levels were significantly increased in all myocardial I/R injury groups when compared with the sham group (Fig. 6A-D, respectively). Increased levels of plasma NF- $\kappa$ B-p65, TNF- $\alpha$, IL- $1 \beta$ and IL-6 were significantly hindered by treatment with glycyrrhizin, with significantly decreased levels exhibited with increased concentrations of glycyrrhizin administered when compared with the NS group $(\mathrm{P}<0.01$; Fig. 6).

Protective effect of glycyrrhizin on HMGBl expression in rats with myocardial I/R injury. To determine the protective

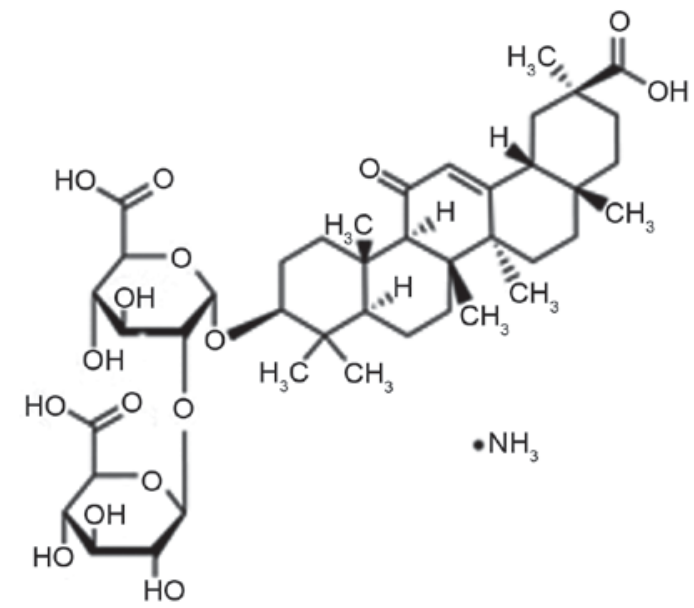

Figure 1. Chemical structure of glycyrrhizin.



Figure 2. Protective effect of glycyrrhizin on infarct size in rats with myocardial I/R injury. Sprague-Dawley rats were divided into five groups: Sham, NS and myocardial I/R injury + pre-treatment with 2,4 and $10 \mathrm{mg} / \mathrm{kg}$ glycyrrhizin groups, respectively, to investigate the effect of glycyrrhizin on infarct size in myocardial I/R injury. Data are presented as the mean \pm standard deviation. ${ }^{\#} \mathrm{P}<0.01$ vs. NS. I/R, ischemia/reperfusion; Sham, sham-treated group; NS, myocardial I/R injury + non-treated group; $2 \mathrm{mg} / \mathrm{kg}$, myocardial I/R injury + pre-treatment with $2 \mathrm{mg} / \mathrm{kg}$ glycyrrhizin group; $4 \mathrm{mg} / \mathrm{kg}$, myocardial I/R injury + pre-treatment with $4 \mathrm{mg} / \mathrm{kg}$ glycyrrhizin group; $10 \mathrm{mg} / \mathrm{kg}$, myocardial I/R injury + pre-treatment with $10 \mathrm{mg} / \mathrm{kg}$ glycyrrhizin group.

effect of glycyrrhizin on HMGB1 expression in myocardial I/R injury rats, HMGB1 miRNA expression was explored in the present study. Fig. 7 demonstrates thatHMGB1 miRNA expression of the sham group was significantly lower than all myocardial I/R injury groups $(\mathrm{P}<0.01)$. Treatment with glycyrrhizin significantly decreased HMGB1 miRNA expression levels in the myocardial I/R injury groups, when compared with the NS group, which exhibited significantly higher miRNA expression levels of HMGB1 in comparison with the sham group $(\mathrm{P}<0.01$; Fig. 7$)$.

Protective effect of glycyrrhizin on ERK protein expression in rats with myocardial I/R injury. The protective effect of glycyrrhizin on ERK protein expression in myocardial I/R injury rats was investigated. The protein expression levels of p-ERK were significantly elevated following myocardial I/R when compared with the sham group ( $\mathrm{P}<0.01$; Fig. 8$)$. There were no significant differences exhibited in the p-ERK protein expression levels of the $2-10 \mathrm{mg} / \mathrm{kg}$ glycyrrhizin-pre-treatment groups; however, levels were elevated in these groups when compared with the sham and NS groups (Fig. 8). 

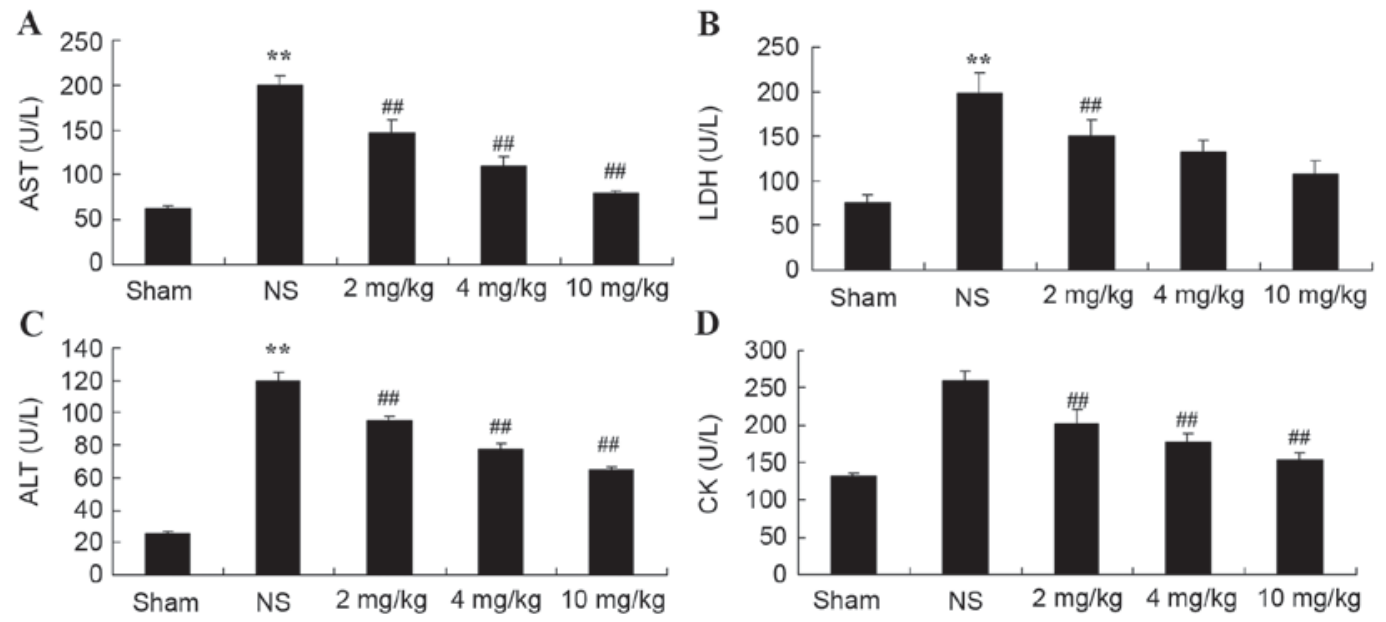

Figure 3. Protective effect of glycyrrhizin on AST, LDH, ALT and CK in rats with myocardial I/R injury. The protective effect of glycyrrhizin was investigated by determining the levels of (A) AST, (B) LDH, (C) ALT and (D) CK in rats with myocardial I/R injury. Rats were divided into five groups: Sham, NS and myocardial I/R injury + pre-treatment with 2,4 and $10 \mathrm{mg} / \mathrm{kg}$ glycyrrhizin groups, respectively, to investigate the effect of glycyrrhizin on infarct size in myocardial I/R injury. Data are presented as the mean \pm standard deviation. ${ }^{* *} \mathrm{P}<0.01 \mathrm{vs}$. Sham; ${ }^{\# \#} \mathrm{P}<0.01$ vs. NS. I/R, ischemia/reperfusion; AST, aspartate aminotransferase; LDH, lactate dehydrogenase; ALT, alanine aminotransferase; CK, creatine kinase; Sham, sham-treated group; NS, myocardial I/R injury + non-treated group; $2 \mathrm{mg} / \mathrm{kg}$, myocardial I/R injury + pre-treatment with $2 \mathrm{mg} / \mathrm{kg}$ glycyrrhizin group; $4 \mathrm{mg} / \mathrm{kg}$, myocardial I/R injury + pre-treatment with $4 \mathrm{mg} / \mathrm{kg}$ glycyrrhizin group; $10 \mathrm{mg} / \mathrm{kg}$, myocardial I/R injury + pre-treatment with $10 \mathrm{mg} / \mathrm{kg}$ glycyrrhizin group.


Figure 4. Protective effect of glycyrrhizin on oxidative stress in myocardial I/R injury rats. Protective effect of glycyrrhizin on the levels of plasma (A) GSH and (B) GSH-PX in rats with myocardial I/R injury. Data are presented as the mean \pm standard deviation. ${ }^{* *} \mathrm{P}<0.01 \mathrm{vs.} \mathrm{Sham;}{ }^{* \#} \mathrm{P}<0.01 \mathrm{vs.} \mathrm{NS}$. GSH, glutathione; GSH-PX, glutathione peroxidase; I/R, ischemia/reperfusion; AST, aspartate aminotransferase; LDH, lactate dehydrogenase; ALT, alanine aminotransferase; CK, creatine kinase; Sham, sham-treated group; NS, myocardial I/R injury + non-treated group; $2 \mathrm{mg} / \mathrm{kg}$, myocardial I/R injury + pre-treatment with $2 \mathrm{mg} / \mathrm{kg}$ glycyrrhizin group; $4 \mathrm{mg} / \mathrm{kg}$, myocardial I/R injury + pre-treatment with $4 \mathrm{mg} / \mathrm{kg}$ glycyrrhizin group; $10 \mathrm{mg} / \mathrm{kg}$, myocardial I/R injury + pre-treatment with $10 \mathrm{mg} / \mathrm{kg}$ glycyrrhizin group.

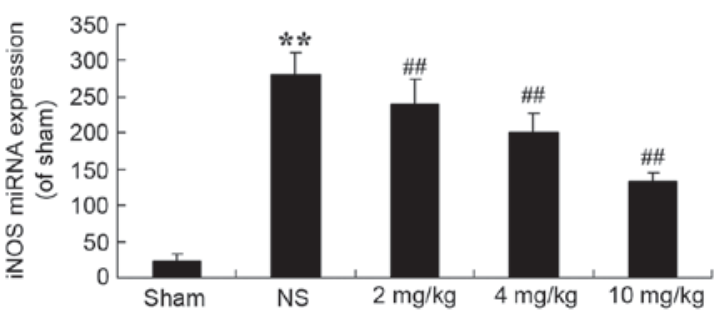

Figure 5. Protective effect of glycyrrhizin on iNOS in myocardial I/R injury rats. To investigate whether the role of the protective effect of glycyrrhizin towards myocardial I/R injury occurs via iNOS production, iNOS miRNA expression levels in rats with myocardial I/R injury were determined. Data are presented as the mean \pm standard deviation. ${ }^{* *} \mathrm{P}<0.01$ vs. Sham; ${ }^{\# \#} \mathrm{P}<0.01$ vs. NS. I/R, ischemia/reperfusion; iNOS, inducible nitric oxide synthase; Sham, sham-treated group; NS, myocardial I/R injury + non-treated group; $2 \mathrm{mg} / \mathrm{kg}$, myocardial I/R injury + pre-treatment with $2 \mathrm{mg} / \mathrm{kg}$ glycyrrhizin group; $4 \mathrm{mg} / \mathrm{kg}$, myocardial I/R injury + pre-treatment with $4 \mathrm{mg} / \mathrm{kg}$ glycyrrhizin group; $10 \mathrm{mg} / \mathrm{kg}$, myocardial I/R injury + pre-treatment with $10 \mathrm{mg} / \mathrm{kg}$ glycyrrhizin group.

Protective effect of glycyrrhizin on p38 and JNK protein expression in rats with myocardial I/R injury. To further demonstrate the protective effect of glycyrrhizin on myocardial I/R injury, the effect on the mitogen-activated protein kinase (MAPK) signaling pathway was explored using western blotting. Protein expression levels of p-p38 and p-JNK were significantly increased after myocardial I/R injury when compared with the sham group $(\mathrm{P}<0.01$; Fig. 9). Pre-treatment with $2-10 \mathrm{mg} / \mathrm{kg}$ glycyrrhizin significantly alleviated these changes in myocardial I/R injury rats when compared with the NS group ( $\mathrm{P}<0.01 ;$ Fig. 9).

\section{Discussion}

In recent years, with the development of the economy and the advancement of internalization, mental states, dietary structures and physical labor intensities have undergone fundamental changes (4). Unfortunately, these changes are not always beneficial to the health of the population. Consequently, the morbidity rates associated with hypertension, hyperlipidemia, diabetes and cardia-cerebrovascular diseases are increasing each year (14). As far as myocardial infarction of ST-elevation type is concerned, approximately two million individuals in 
A



B



D



Figure 6. Protective effect of glycyrrhizin on inflammatory reactions in myocardial I/R injury rats. Protective effect of glycyrrhizin on plasma (A) NF- $\kappa$ B-p65, (B) TNF- $\alpha,(C)$ IL-1 $\beta$ and (D) IL-6 levels in rats with myocardial I/R injury. Data are presented as the mean \pm standard deviation. ${ }^{* *} \mathrm{P}<0.01$ vs. Sham; ${ }^{\# \#} \mathrm{P}<0.01$ vs. NS. I/R, ischemia/reperfusion; NF- $\kappa \mathrm{B}-\mathrm{p} 65$, nuclear factor kappa-light-chain-enhancer of activated B cells-p65; TNF- $\alpha$, tumor necrosis factor- $\alpha$; IL-1 $\beta$, interleukin-1 $\beta$; IL-6, interleukin-6; Sham, sham-treated group; NS, myocardial I/R injury + non-treated group; 2 mg/kg, myocardial I/R injury + pre-treatment with $2 \mathrm{mg} / \mathrm{kg}$ glycyrrhizin group; $4 \mathrm{mg} / \mathrm{kg}$, myocardial I/R injury + pre-treatment with $4 \mathrm{mg} / \mathrm{kg}$ glycyrrhizin group; $10 \mathrm{mg} / \mathrm{kg}$, myocardial I/R injury + pre-treatment with $10 \mathrm{mg} / \mathrm{kg}$ glycyrrhizin group.

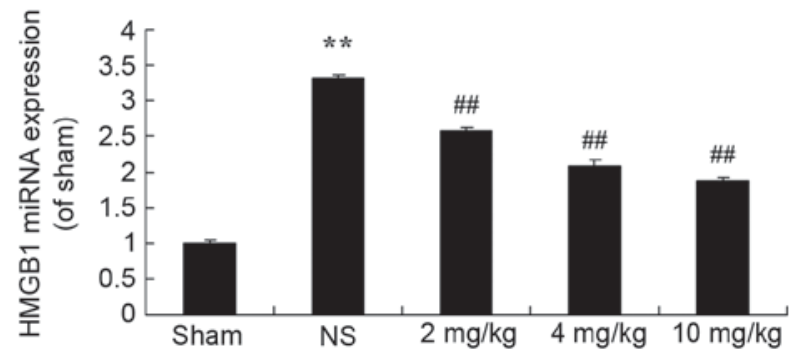

Figure 7. Protective effect of glycyrrhizin on HMGB1 expression in myocardial I/R injury rats. Statistical analysis of the protective effect of glycyrrhizin on HMGB1 miRNA expression in rats with myocardial I/R injury. Data are presented as the mean \pm standard deviation. ${ }^{* *} \mathrm{P}<0.01$ vs. the Sham group; ${ }^{\# \#} \mathrm{P}<0.01$ vs. the NS group. I/R, ischemia/reperfusion; HMGB1, high-mobility group box 1; NS, myocardial I/R injury + non-treated group; $2 \mathrm{mg} / \mathrm{kg}$, myocardial I/R injury + pre-treatment with $2 \mathrm{mg} / \mathrm{kg}$ glycyrrhizin group; $4 \mathrm{mg} / \mathrm{kg}$, myocardial I/R injury + pre-treatment with $4 \mathrm{mg} / \mathrm{kg}$ glycyrrhizin group; $10 \mathrm{mg} / \mathrm{kg}$, myocardial I/R injury + pre-treatment with $10 \mathrm{mg} / \mathrm{kg}$ glycyrrhizin group.

China are diagnosed with myocardial infarction and 500,000 new cases present with myocardial infarction (15). The number of cases of acute myocardial infarction in $1991(1,492)$ were 2.47 times greater than the cases noted in 1972 (604) in 16 large- and medium-sized hospitals located in Beijing (16). In the present study, the protective effect of glycyrrhizin notably inhibited infarct size and plasma AST, LDH, ALT and CK levels in rats with myocardial I/R injury. Zhang et al (17) indicated that glycyrrhizin protected the brain against ischemia-reperfusion injury in mice. Zhai et al demonstrated that glycyrrhizin protected the heart against I/R injury, through the blockade of HMGB1 and the phospho-JNK pathway (18).

Neutrophil granulocytes are 'the power plant' of oxygen radicals, with damaging effects that exceed the protective effect of myocardium (19). Infusion of hemameba into the heart with isolated perfusion has been demonstrated to result in I/R (20). These findings support the theory that neutrophil granulocytes have pathogenic effects in myocardial $\mathrm{I} / \mathrm{R}$ injury (21). To reduce the effects of myocardial infiltration, neutrophils may predominantly reduce the discharge of oxygen radicals. This effect may relieve stunned myocardium after ischemia and shorten the duration of stunned myocardium, which would relieve the degrees of myocardial I/R injury and shorten the duration required to protect myocardial $I / R$ injury (22). The present study demonstrated that pretreatment with $2-10 \mathrm{mg} / \mathrm{kg}$ glycyrrhizin significantly elevated plasma GSH and GSH-PX levels in rats with myocardial I/R injury. Wang et al reported that glycyrrhizic acid attenuated reactive oxygen species production in the kidneys of diabetic mice (23). Rahman and Sultana (10) reported that glycyrrhizin inhibited 12-O-tetradecanoyl phorbol-13-acetate-induced cutaneous oxidative stress in Swiss albino mice.

iNOS is not calcium-dependent and rarely exhibits expression in normal tissues (24). When stimulated by inflammation, iNOS maybe expressed in any cells, not only immuno-reactive cells, such as mononuclear cells, mastocytes and neutrophils, but also in cancer and cardiovascular cells (25). Within the cardiovascular system, iNOS enzyme is predominantly expressed in blood vessel endothelium, myocardium and vascular smooth cells. When endothelial cells are stimulated by cytokines as a result of inflammation, expression of endothelial NOS is inhibited (26). Subsequently, high concentrations of NO may be catalyzed (27). Previous findings have revealed that the production of NO by iNOS is important in the development of cellular damages in various inflammatory diseases (26). In the present study, I/R-induced myocardial injury of rat hearts subjected to pre-treatment with glycyrrhizin revealed significantly decreased iNOS miRNA expression levels. Similarly, Kim et al concluded that glycyrrhizin reduced HMGB1 secretion, reduced hepatic injury and the expression of iNOS (28).

Previous studies have indicated that TNF- $\alpha$ levels after myocardial ischemia are significantly increased (29). For 
A

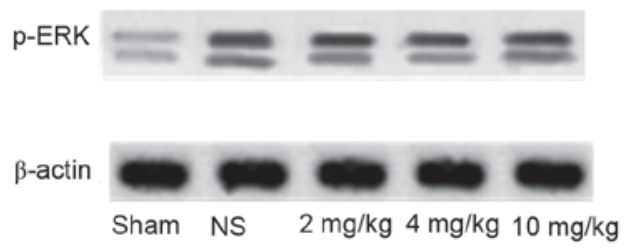

B

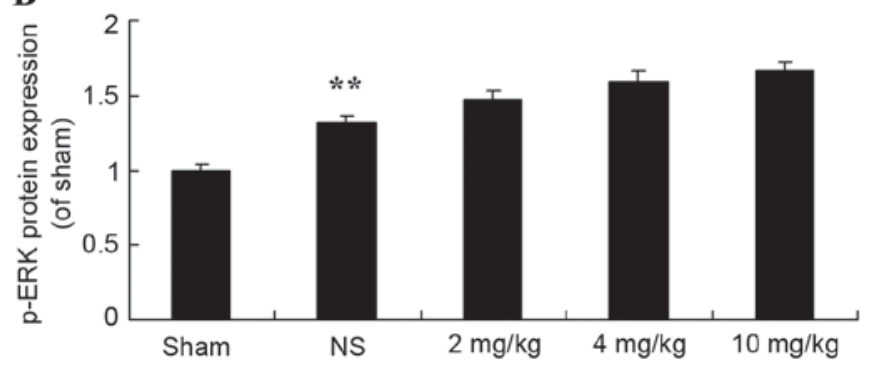

Figure 8. Protective effect of glycyrrhizin on ERK protein expression in myocardial I/R injury rats. (A) Protective effect of glycyrrhizin on p-ERK protein expression using western blotting analysis and (B) statistical analysis of $\mathrm{p}$-ERK protein expression in rats with myocardial I/R injury. Data are presented as the mean \pm standard deviation. ${ }^{* *} \mathrm{P}<0.01$ vs. the Sham group; ${ }^{* \#} \mathrm{P}<0.01$ vs. the NS group. $\mathrm{I} / \mathrm{R}$, ischemia/reperfusion; $\mathrm{p}$-ERK, phosphorylated extracellular signal-regulated kinase; $\mathrm{NS}$, myocardial I/R injury + non-treated group; $2 \mathrm{mg} / \mathrm{kg}$, myocardial I/R injury + pre-treatment with $2 \mathrm{mg} / \mathrm{kg}$ glycyrrhizin group; $4 \mathrm{mg} / \mathrm{kg}, \mathrm{myocardial} \mathrm{I} / \mathrm{R}$ injury + pre-treatment with $4 \mathrm{mg} / \mathrm{kg}$ glycyrrhizin group; $10 \mathrm{mg} / \mathrm{kg}$, myocardial I/R injury + pre-treatment with $10 \mathrm{mg} / \mathrm{kg}$ glycyrrhizin group.

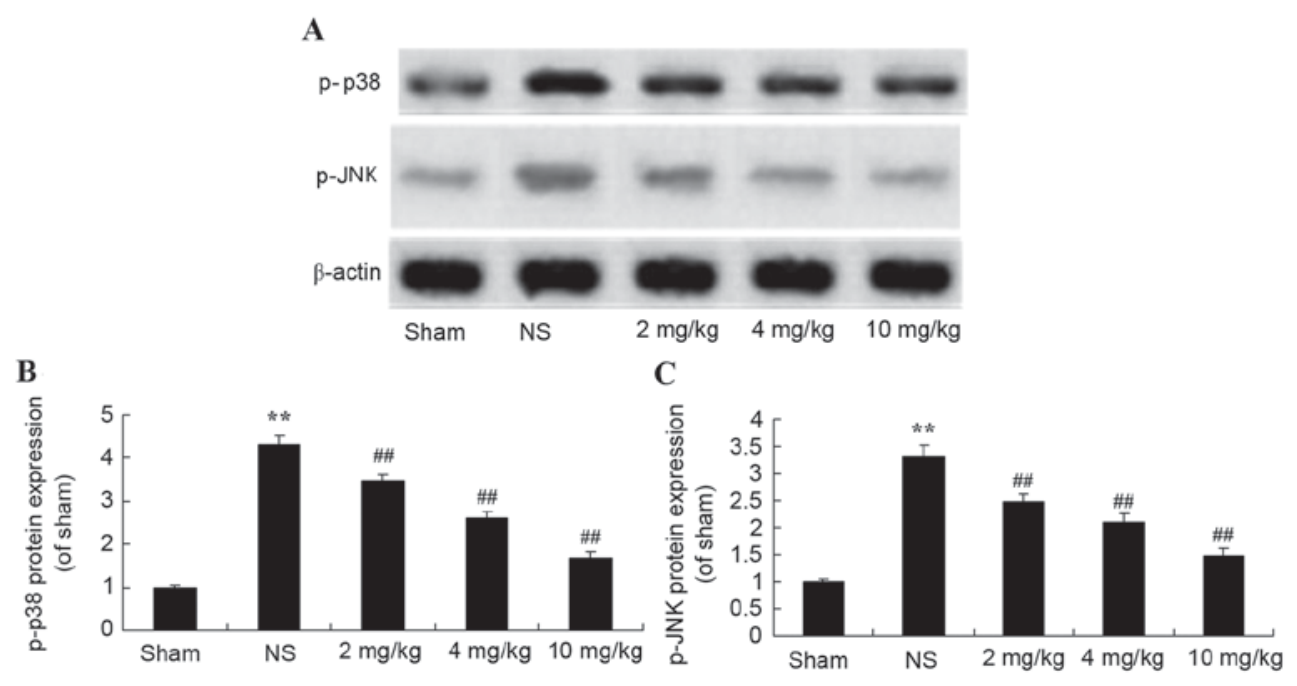

Figure 9. Protective effect of glycyrrhizin on p-p38 and p-JNK protein expression in myocardial I/R injury rats. (A) Protective effect of glycyrrhizin on p-p38 and p-JNK protein expression using western blot analysis and statistical analysis of (B) p-p38 and (C) p-JNK protein expression in myocardial I/R injury rats. Data is presented as the mean \pm standard deviation. ${ }^{* *} \mathrm{P}<0.01$ vs. the Sham group; ${ }^{\# \#} \mathrm{P}<0.01$ vs. the NS group. I/R, ischemia/reperfusion; $\mathrm{p}$, phosphorylated; p38, p38 mitogen-activated protein kinase; JNK, c-Jun N-terminal kinase; NS, myocardial I/R injury + non-treated group; $2 \mathrm{mg} / \mathrm{kg}, \mathrm{myocardial} \mathrm{I/R} \mathrm{injury} \mathrm{+}$ pre-treatment with $2 \mathrm{mg} / \mathrm{kg}$ glycyrrhizin group; $4 \mathrm{mg} / \mathrm{kg}$, myocardial I/R injury + pre-treatment with $4 \mathrm{mg} / \mathrm{kg}$ glycyrrhizin group; $10 \mathrm{mg} / \mathrm{kg}$, myocardial I/R injury + pre-treatment with $10 \mathrm{mg} / \mathrm{kg}$ glycyrrhizin group.

patients with acute myocardial infarction or unstable angina, levels of IL-1 $\beta$, SIL-2R, IL- 6 and TNF- $\alpha$ are significantly increased. Following four months of follow-up, these levels are significantly decreased (30). For patients with acute or chronic coronary artery diseases, both IFN- $\gamma$ and TNF- $\alpha$ are significantly increased. Intervention of TNF- $\alpha$ may improve myocardial ischemia, with the time of intervention being either before reperfusion or at the beginning of reperfusion (31). Intervention at the beginning of reperfusion was discovered to have an influential role in the recovery of myocardium (31). It is therefore feasible to consider the inflammatory factor TNF- $\alpha$, as a useful treatment at the beginning of reperfusion (29). TNF- $\alpha$ levels are increased in MI/RI and the process of percutaneous coronary intervention, thus MI/RI may be protected by a mechanism involving TNF- $\alpha$ (29). In the present study, pre-treatment with glycyrrhizin significantly inhibited plasma NF- $\kappa B-p 65$ TNF- $\alpha$, IL-1 $\beta$ and IL-6 levels in rats with myocardial I/R injury. Michaelis et al (32) reported that glycyrrhizin may have anti-oxidative and anti-inflammatory effects in
H5N1 influenza A virus-infected cells, through reducing the activation of JNK and p38. HMGB-1 is a highly conservative nucleoprotein that is released by necrotic or injured cells and secreted by mononuclear cells, and/or macrophages, which react with endogenous and exogenous non-inflammatory stimuli (33). HMGB-1 is secreted out of cells by non-classical and mediated secretory pathways, with HMGB-1 secretion occurring later than pro-inflammatory cytokines, including tumor necrosis factors (such as IL-1). HMGB-1 is considered to be an important late pro-inflammatory cytokine (34). Extracellular HMGB-1 has dual roles in the immune response during inflammation (35). While necrotic cells may release HMGB-1 and activate early inflammatory responses to eliminate foreign matters and therefore promote the repair of injured tissues or organs (36), mononuclear macrophages may secrete HMGB-1 to activate late non-inflammatory responses (37). Affected by chemotactic factors, more inflammatory cells subsequently infiltrate injured tissues and aggravate pathological injuries. Extracellular HMGB-1 requires association with 
corresponding cell-membrane receptors to exert its biological effects (38). Notably, the present study indicated that treatment with glycyrrhizin effectively decreased HMGB1 miRNA expression levels in rats with myocardial I/R injury. However, Ni et al (39) reported that the neuroprotective effect of glycyrrhizin prevents spinal cord I/R injury, through inflammatory cytokines and HMGB-1 expression.

The morbidity rates associated with cardiovascular disease are increasing each year, and this disease accounts for one of the highest mortality rates (40). In the occurrence and development of various cardiovascular diseases, including diabetic cardiomyopathy, MI/RI and drug-induced cardiomyopathy, the activation of MAPK has an essential role. This is due to the fact that various stimuli regulate genetic expression levels and changes of protein functions by activating signal transduction pathways in MAPK, thus myocardial damages may be induced or aggravated (41). In the present study, glycyrrhizin significantly alleviated p38 and JNK protein expression levels and did not exhibit notable effects on ERK protein expression in myocardial I/R injury rats. Michaelis et al (32) reported that glycyrrhizin induced anti-oxidative and anti-inflammatory effects in H5N1 influenza A virus-infected cells by reducingthe activation of JNK and p38. Furthermore, Honda et al (42) revealed that glycyrrhizin suppressed LPS-induced activation by inhibiting the activation of MAPKs (JNK and p38) signaling via a different manner.

In conclusion, the present results demonstrated that the protective effect of glycyrrhizin attenuated myocardial I/R injury in rats. The protective effect of glycyrrhizin on oxidative stress, iNOS and inflammatory reactions was revealed in vivo, through triggering HMGB1 and the blockage of the p38 and JNK pathways. These data suggest a novel therapeutic approach for the treatment of ischemic stroke with glycyrrhizin.

\section{References}

1. Yao T, Lu W, Zhu J, et al: Role of CD11b+Gr-1+ myeloid cells in AGEs-induced myocardial injury in a mice model of acute myocardial infarction. Int J Clin Exp Pathol 8: 3238-3249, 2015.

2. Valls N, Gormaz JG, Aguayo R, González J, Brito R, Hasson D, Libuy M, Ramos C, Carrasco R, Prieto JC, et al: Amelioration of persistent left ventricular function impairment through increased plasma ascorbate levels following myocardial infarction. Redox Rep 21: 75-83, 2016.

3. Sun Z, Zeng J and Huang H: Intracoronary injection of tirofiban prevents microcirculation dysfunction during delayed percutaneous coronary intervention in patients with acute myocardial infarction. Int J Cardiol 208: 137-140, 2016.

4. Mulla ZD, Wilson B, Abedin Z, Hernandez LL and Plavsic SK Acute myocardial infarction in pregnancy: A statewide analysis. J Registry Manag 42: 12-17, 2015.

5. Bergmeijer TO, Janssen PW, Schipper JC, Qaderdan K, Ishak M, Ruitenbeek RS, Asselbergs FW, van 't Hof AW, Dewilde WJ, Spanó F, et al: CYP2C19 genotype-guided antiplatelet therapy in ST-segment elevation myocardial infarction patients-Rationale and design of the Patient Outcome after primary PCI (POPular) Genetics study. Am Heart J 168: 16-22.e1, 2014.

6. Ota S, Tanimoto T, Hirata K, Orii M, Shiono Y, Shimamura K, Ishibashi K, Yamano T, Ino Y, Kitabata H, et al: Assessment of circumferential endocardial extent of myocardial edema and infarction in patients with reperfused acute myocardial infarction: A cardiovascular magnetic resonance study. Int Heart J 55: 234-238, 2014

7. Liehn EA, Tuchscheerer N, Kanzler I, Drechsler M, Fraemohs L, Schuh A, Koenen RR, Zander S, Soehnlein O, Hristov M, et al: Double-edged role of the CXCL12/CXCR4 axis in experimental myocardial infarction. J Am Coll Cardiol 58: 2415-2423, 2011.
8. Hu PY, Wang YW, Pang XH and Wang HW: T174M polymorphism in the angiotensinogen gene and risk of myocardial infarction: A meta-analysis. Genet Mol Res 14: 3767-3774, 2015.

9. Jose R, Sajitha GR and Augusti KT: A review on the role of nutraceuticals as simple as se(2+) to complex organic molecules such as glycyrrhizin that prevent as well as cure diseases. Indian J Clin Biochem 29: 119-132, 2014.

10. Rahman S and Sultana S: Glycyrrhizin exhibits potential chemopreventive activity on 12-O-tetradecanoyl phorbol-13-acetate-induced cutaneous oxidative stress and tumor promotion in Swiss albino mice. J Enzyme Inhib Med Chem 22: 363-369, 2007.

11. He SQ, Gao M, Fu YF and Zhang YN: Glycyrrhizic acid inhibits leukemia cell growth and migration via blocking AKT/mTOR/STAT3 signaling. Int J Clin Exp Pathol 8: 5175-5181, 2015.

12. Livak KJ and Schmittgen TD: Analysis of relative gene expression data using real-tie quantitative PCR and the 2(-Delta Delta C(T)) Method. Methods 25: 402-408, 2001.

13. Geng ZH, Huang L, Song MB and Song YM: Protective effect of a polysaccharide from Salvia miltiorrhiza on isoproterenol (ISO)-induced myocardial injury in rats. Carbohydr Polym 132: 638-642, 2015.

14. Husebye T, Eritsland J, Arnesen H, Bjørnerheim R, Mangschau A, Seljeflot I and Andersen GØ: Association of interleukin 8 and myocardial recovery in patients with ST-elevation myocardial infarction complicated by acute heart failure. PLoS One 9: e112359, 2014.

15. Tilling L, Hunt J, Donald A, Clapp B and Chowienczyk P: Darbepoetin enhances endothelium-dependent vasomotor function in patients with stable coronary artery disease only after preceding ischaemia/reperfusion. Clin Sci (Lond) 122: 329-336, 2012.

16. Yang XC, Liu Y, Wang LF, Cui L, Wang T, Ge YG, Wang HS, Li WM, Xu L, Ni ZH, et al: Reduction in myocardial infarct size by postconditioning in patients after percutaneous coronary intervention. J Invasive Cardiol 19: 424-430, 2007.

17. Zhang J, Wu Y, Weng Z, Zhou T, Feng T and Lin Y: Glycyrrhizin protects brain against ischemia-reperfusion injury in mice through HMGB1-TLR4-IL-17A signaling pathway. Brain Res 1582: 176-186, 2014.

18. Zhai CL, Zhang MQ, Zhang Y, Xu HX, Wang JM, An GP, Wang YY and Li L: Glycyrrhizin protects rat heart against ischemia-reperfusion injury through blockade of HMGB1-dependent phospho-JNK/Bax pathway. Acta Pharmacol Sin 33: 1477-1487, 2012.

19. Dong W, Zhou M, Dong M, Pan B, Liu Y, Shao J, Gu X, Huang Y, Li G, Wang Y and Sun H: Keto acid metabolites of branched-chain amino acids inhibit oxidative stress-induced necrosis and attenuate myocardial ischemia-reperfusion injury. J Mol Cell Cardiol 101: 90-98, 2016.

20. Chan W, Taylor AJ, Ellims AH, Lefkovits L, Wong C, Kingwell BA, Natoli A, Croft KD, Mori T, Kaye DM, et al: Effect of iron chelation on myocardial infarct size and oxidative stress in ST-elevation-myocardial infarction. Circ Cardiovasc Interv 5: 270-278, 2012

21. Wang Z, Wang Y, Ye J, Lu X, Cheng Y, Xiang L, Chen L, Feng W, Shi H, Yu X, et al: bFGF attenuates endoplasmic reticulum stress and mitochondrial injury on myocardial ischaemia/reperfusion via activation of PI3K/Akt/ERK1/2 pathway. J Cell Mol Med 19: 595-607, 2015.

22. Mura M, Hopkins TG, Michael T, Abd-Latip N, Weir J, Aboagye E, Mauri F, Jameson C, Sturge J, Gabra H, et al: LARP1 post-transcriptionally regulates mTOR and contributes to cancer progression. Oncogene 34: 5025-5036, 2015.

23. Wang ZH, Hsieh CH, Liu WH and Yin MC: Glycyrrhizic acid attenuated glycative stress in kidney of diabetic mice through enhancing glyoxalase pathway. Mol Nutr Food Res 58: 1426-1435, 2014.

24. Zaitone SA and Abo-Gresha NM: Rosuvastatin promotes angiogenesis and reverses isoproterenol-induced acute myocardial infarction in rats: Role of iNOS and VEGF. Eur J Pharmacol 691: 134-142, 2012.

25. Ye Y, Perez-Polo JR and Birnbaum Y: Protecting against ischemia-reperfusion injury: Antiplatelet drugs, statins and their potential interactions. Ann N Y Acad Sci 1207: 76-82, 2010.

26. Chen TH, Liao FT, Yang YC and Wang JJ: Inhibition of inducible nitric oxide synthase ameliorates myocardial ischemia/reperfusion injury-induced acute renal injury. Transplant Proc 46: 1123-1126, 2014 
27. Hu Q,Zhou D, Li X, Yang N, Guo P, Xu D and Li X: Renoprotective effects of propofol on the expression of iNOS protein in rats with ischemia reperfusion injury. Int J Clin Exp Med 8: 776-780, 2015.

28. Kim YM, Kim HJ and Chang KC: Glycyrrhizin reduces HMGB1 secretion in lipopolysaccharide-activated RAW 264.7 cells and endotoxemic mice by $\mathrm{p} 38 / \mathrm{Nrf} 2$-dependent induction of HO-1. Int Immunopharmacol 26: 112-118, 2015.

29. Kleinbongard P, Schulz R and Heusch G: TNFo in myocardial ischemia/reperfusion, remodeling and heart failure. Heart Fail Rev 16: 49-69, 2011.

30. Yung MM, Chan DW, Liu VW, Yao KM and Ngan HY: Activation of AMPK inhibits cervical cancer cell growth through AKT/FOXO3a/FOXM1 signaling cascade. BMC Cancer 13: 327, 2013.

31. Hu G, Huang X, Zhang K, Jiang $\mathrm{H}$ and $\mathrm{Hu} X$ : Anti-inflammatory effect of B-type natriuretic peptide postconditioning during myocardial ischemia-reperfusion: Involvement of PI3K/Akt signaling pathway. Inflammation 37: 1669-1674, 2014.

32. Michaelis M, Geiler J, Naczk P, Sithisarn P, Leutz A, Doerr HW and Cinatl J Jr: Glycyrrhizin exerts antioxidative effects in H5N1 influenza A virus-infected cells and inhibits virus replication and pro-inflammatory gene expression. PLoS One 6: e19705, 2011.

33. Xiong J, Wang Q, Xue FS, Yuan YJ, Li S, Liu JH, Liao X and Zhang YM: Comparison of cardioprotective and anti-inflammatory effects of ischemia pre- and postconditioning in rats with myocardial ischemia-reperfusion injury. Inflamm Res 60 : 547-554, 2011.

34. Nogueira-Machado JA and de Oliveira Volpe CM: HMGB-1 as a target for inflammation controlling. Recent Pat Endocr Metab Immune Drug Discov 6: 201-209, 2012.

35. Dejean E, Foisseau M, Lagarrigue F, Lamant L, Prade N, Marfak A, Delsol G, Giuriato S, Gaits-Iacovoni F and Meggetto F: ALK+ALCLs induce cutaneous, HMGB-1-dependent IL-8/CXCL8 production by keratinocytes through NF- $\mathrm{kB}$ activation. Blood 119: 4698-4707, 2012.
36. Qiu J, Nishimura M, Wang Y, Sims JR, Qiu S, Savitz SI, Salomone $\mathrm{S}$ and Moskowitz MA: Early release of HMGB-1 from neurons after the onset of brain ischemia. J Cereb Blood Flow Metab 28: 927-938, 2008

37. Frost RA, Nystrom G, Burrows PV and Lang CH: Temporal differences in the ability of ethanol to modulate endotoxin-induced increases in inflammatory cytokines in muscle under in vivo conditions. Alcohol Clin Exp Res 29: 1247-1256, 2005.

38. Tao X, Sun X, Yin L, Han X, Xu L, Qi Y, Xu Y, Li H, Lin Y, Liu K and Peng J: Dioscin ameliorates cerebral ischemia/reperfusion injury through the downregulation of TLR4 signaling via HMGB-1 inhibition. Free Radic Biol Med 84: 103-115, 2015.

39. Ni B, Cao Z and Liu Y: Glycyrrhizin protects spinal cord and reduces inflammation in spinal cord ischemia-reperfusion injury. Int J Neurosci 123: 745-751, 2013.

40. Pando R, Cheporko Y, Haklai R, Maysel-Auslender S, Keren G, George J, Porat E, Sagie A, Kloog Y and Hochhauser E: Ras inhibition attenuates myocardial ischemia-reperfusion injury. Biochem Pharmacol 77: 1593-1601, 2009.

41. Jeong CW, Yoo KY, Lee SH, Jeong HJ, Lee CS and Kim SJ: Curcumin protects against regional myocardial ischemia/reperfusion injury through activation of RISK/GSK-3 $\beta$ and inhibition of p38 MAPK and JNK. J Cardiovasc Pharmacol Ther 17: 387-394, 2012.

42. Honda H, Nagai Y, Matsunaga T, Saitoh S, Akashi-Takamura S, Hayashi H, Fujii I, Miyake K, Muraguchi A and Takatsu K: Glycyrrhizin and isoliquiritigenin suppress the LPS sensor toll-like receptor 4/MD-2 complex signaling in a different manner. J Leukoc Biol 91: 967-976, 2012. 